\title{
DIODE LASER PHOTOCOAGUALTION AS A NOVEL METHOD FOR SOCKET SEALING DURING ALVEOLAR SOCKET PRESERVATION
}

\author{
Ahmed A. Kamal El Din ${ }^{{ }^{*}} B D S$, Maha A. Abou Khadr ${ }^{2} P h D$, Maha R. \\ Taalab ${ }^{3} P h D$
}

\begin{abstract}
INTRODUCTION: Socket preservation is a procedure after tooth extraction to limit the post-extraction reduction of the ridge volume. Noncontact laser photocoagulation is a simple and atraumatic method used for socket sealing.

Objectives: Compare the effect of diode laser photocoagulation to non-resorbable dense polytetraflouoroethylene (d-PTFE) membrane on bone dimensional changes.

MATERIALS AND METHODS: Thirty-six patients ( $\mathrm{n}=18$ for each group) with non-restorable maxillary anterior or premolar teeth were included in this study. After extraction, sites were grafted with deproteinized bovine bone xenograft and sealed either with laser photocoagulation or a non-resorbable d-PTFE membrane. Measurements of the alveolar bone width were performed on cone beam computed tomographs, taken at baseline before and four months after extraction.

RESULTS: Both groups showed a reduction in bone width. At the crest, the mean amount of reduction was $0.69(0.33) \mathrm{mm}$ and $0.78(0.15)$ $\mathrm{mm}$ for laser and membrane groups, respectively. As for the middle third, less reduction was observed with a mean of $0.56(0.36) \mathrm{mm}$ and $0.58(0.18) \mathrm{mm}$ for laser and membrane groups, respectively. The least amount of reduction was in the apical third with a mean of 0.26 (0.36) $\mathrm{mm}$ and $0.41(0.17) \mathrm{mm}$ for laser and membrane groups, respectively. However, this reduction in bone dimensions was insignificant between both groups.

CONCLUSION: Laser photocoagulation is as effective as the d-PTFE membranes in sealing sockets after grafting.
\end{abstract}

KEYWORDS: Diode laser, photocoagulation, d-PTFE membrane, socket preservation, xenograft.

1 Demonstrator at Faculty of Dentistry, Alexandria, Egypt.

2Professor of Oral Medicine, Periodontology, Oral Diagnosis and Oral Radiology, Faculty of Dentistry, Alexandria University, Alexandria, Egypt.

3 Assistant Professor of Oral Medicine, Periodontology, Oral Diagnosis and Oral Radiology, Faculty of Dentistry, Alexandria University, Alexandria, Egypt.

*Corresponding author:

E-mail: dr.ahmed.ashraf1991@gmail.com

\section{INTRODUCTION}

Maintaining a healthy, functional, and esthetic natural dentition remains the main goal of periodontal therapy (1, 2). However, dental extraction is sometimes inevitable under certain circumstances. Proper handling of the extraction site aims to optimize the alveolar ridge profile either for future implant placement or tooth replacement with a fixed partial denture (3).

Histologically, the lining of socket wall contacting the periodontal ligament is composed of lamellar bone known as bundle bone (4) with a thickness of $0.2-0.4 \mathrm{~mm}$ (5). Bundle bone is considered to be a tooth dependent structure, meaning that tooth extraction will cause the loss of the bundle bone (4). The thickness of the buccal plate of bone in the anterior maxilla was found to be less than $1 \mathrm{~mm}$ in most sites and $50 \%$ of the examined sites were less than $0.5 \mathrm{~mm}$ in thickness (6). Therefore, after tooth extraction, resorption of the buccal plate of bone is expected, mostly at the crest correlated to the disruption of its vascular supply from the periodontal ligament and prominent osteoclastic activity (7). The magnitude of this resorption declines gradually in an apical direction (8).
Tooth extraction leads to a considerable decrease in the width of the alveolar ridge up to $50 \%$. Two-thirds of this loss occurs in the first three months (9). This reduction is more pronounced in the crest of the buccal plate of bone (10). Nonetheless, adequate alveolar ridge volume is needed for implant placement. This requires a bone width of 6-7 $\mathrm{mm}$ for proper positioning guided by the future prosthodontic restoration (11).

The efficacy of various socket preservation treatment modalities was proved to significantly reduce the bone dimensional changes after tooth extraction .Socket grafts include autogenous bone, allografts, xenografts, alloplasts , polylactic acid and polyglycolic acid sponges $(12,13)$.

Earlier studies of ridge preservation techniques demonstrated good dimensional preservation using deproteinized bovine bone mineral (DBBM) and was recognized as a gold standard biomaterial for alveolar socket preservation over the past 10 years $(14,15)$. Araujo et al. reported that using bovine bone in alveolar socket preservation resulted in less ridge resorption compared to that of autogenous bone (16). The main goals comprise the limitation of post-extraction ridge volume alterations and the stimulation of healing of soft and hard tissue (17). 
Kamal El din et al.

However, socket preservation techniques may minimize, but do not completely prevent the collapse of the alveolar process. Therefore, limited alveolar process deficiency will be expected even after alveolar socket preservation (12, 18).

Type I extraction sockets according to Elian classification in 2007 have an intact labial plate of bone and no soft tissue recession. Therefore, it does not require a mucoperiosteal flap elevation, only bone graft particles are packed into the socket after atraumatic extraction and socket debridement, then sealed with barrier membranes or soft tissue grafts $(19,20)$.

Dense polytetrafluoroethylene

(d-PTFE) membranes are also widely used in socket preservation procedures due to their small pore size $<0.2 \mu \mathrm{m}$ that resists bacterial invasion into their structure and can be left exposed intraorally with a low risk of infection (21). Therefore, they are effective without complete soft tissue coverage, as flap advancement yields increased postoperative pain and narrower zones of keratinized tissue (22).

The use of diode lasers in soft tissue surgery in the oral cavity is extremely helpful because they are highly absorbed by the tissue chromophores, such as melanin, hemoglobin, and collagen, also because of their ability to cut, coagulate and achieve hemostasis (23).

Diode laser photocoagulation is a touchless technique by which the laser power output of $1-3$ watts is released in a continuous mode over the target area at a distance of 2 to $3 \mathrm{~mm}$ from the surface and coagulates to a depth of approximately 7 to $10 \mathrm{~mm}(24,25)$. The efficacy of the $980 \mathrm{~nm}$ diode laser photothermal coagulation has previously been investigated experimentally by Mirdan et al. in the coagulation of non-grafted extraction sockets to provide a dressing to the wound site by the formation of a stable blood clot (26).

The null hypothesis of the present study was that the effect of diode laser photocoagulation in sealing the alveolar sockets during socket preservation is similar to the effect of the non-resorbable d-PTFE membrane and that both methods are equally effective in preserving the underlying bone graft particles to control the postextraction ridge dimensional changes.

The aim of this randomized control clinical trial was to compare the effect of diode laser photocoagulation to the effect of d-PTFE membrane in the preservation of the horizontal bone width after socket preservation.

\section{MATERIALS AND METHODS}

The present study was approved by the research ethics committee of the Faculty of Dentistry, Alexandria University, and registered in ClinicalTrials.gov with the protocol ID: NCT04353999.

Thirty-six patients (14 males, 22 females, aged 2250 years) participated in this randomized controlled clinical trial from March 2019 to March 2020. They were recruited from the outpatient clinic of the Oral Medicine, Periodontology, Oral Diagnosis And Oral Radiology department, faculty of dentistry, Alexandria University in 2019.

The inclusion criteria were; non-restorable maxillary anterior and premolar teeth for untreatable caries, endodontic
Effect of laser photocoagulation in socket preservation. treatment failure or root fracture with no acute symptoms. Type I post-extraction sockets with all bony walls intact (1). All participants had a good standard of oral hygiene, as determined by the registration of an O'Leary Plaque Index (2) of less than or equal to $10 \%$ after phase I therapy.

The exclusion criteria were; the presence of any systemic disease that could complicate bone and soft tissue healing of the grafted socket or interfere with extraction such as tooth ankylosis, smoking, the presence of bone dehiscence and fenestrations of the post-extractive alveolus (Type II and III sockets) (19). Subjects who had undergone radiation therapy or who were under bisphosphonate therapy were also excluded.

All patients who signed the informed consent and matched the eligibility criteria were randomly allocated using a computer random allocation software (28) into two study groups with a ratio of $1: 1$. In both groups, socket preservation was achieved using bovine bone xenograft???? In group 1, d-PTFE membrane (Permamem, Botiss) was used to seal the sockets after bone grafting, whereas for group 2, $980 \mathrm{~nm}$ diode laser photocoagulation was used to seal the sockets after grafting.

Each allocation was represented by a code representing the study group that it was assigned to, and was sealed in sequentially numbered opaque envelopes that will be only opened at the time of intervention by the supervisor.

The enrolled participants were equally prepared for the surgical procedure prior to opening the envelope on the day of surgery

Participants were blinded from their study group they were assigned to. Blinding of the operator was not applicable whereas the outcome assessor and the statistician were blinded.

Maxillary alginate impressions were taken for all patients to fabricate a radiographic stent that the patient will wear during the preoperative radiograph.

Radiographic evaluation and radiographic stent fabrication

After alginate impressions were poured using extra hard stone , 2 holes were then drilled on the occlusal aspect of the remaining root in the mid buccal and mid palatal points using a No1/4 rosehead bur mounted on a low-speed straight handpiece with a direction of drilling parallel to the long axis of the ridge contour on the cast. 2 wires were inserted in 2 holes parallel to each other then a condensation silicone putty was used afterward to block the undercuts and relieve the stent away from the tissue contours on the cast. This was done to ease the identification of the soft tissue contour on the radiographs as the stent and the soft tissue have similar radiodensities.

A $2 \mathrm{~mm}$ hard vacuum sheet was then pressed over the cast and adapted around the wires. The stent was then removed from the cast, the excess tray material was removed and the edges were finished. The wires extending out of the stent were also trimmed away from the tissues (Fig.1).

\section{Imaging}

A preoperative CBCT was made for the tooth to be extracted while the patient wore the radiographic stent for the examination of the alveolar housing around the tooth to 
Kamal El din et al.

match the inclusion criteria of having an intact buccal plate of bone, classified as type I extraction socket (19). An (iCAT FLX V17 cone beam computed tomography machine, USA) was used for the procedure. Patients matching the clinical and radiographic eligibility criteria were then enrolled into the study and provided with a detailed explanation of the procedure and its benefits. Once the patients approved the intervention and compliance to the recall visits, they were given written informed consent translated to Arabic to sign.

\section{Surgical procedure}

Oral hygiene instructions were given to the enrolled patients. Patients were randomly assigned to one of the two groups preoperatively on the day of the surgery.

After administration of local anesthesia, a crestal incision was done around the tooth to be extracted using a 15c blade (Swan Morton, England). A periotome (Nordent, USA) was then used to luxate the tooth by severing the periodontal ligament, then maxillary anterior or premolar forceps were used to extract the tooth atraumatically to preserve the alveolar housing and the soft tissue. The socket was then irrigated with sterile saline and $0.12 \%$ chlorhexidine gluconate and curettage were done using a bone curette in the periapical area to ensure removal of any granulation tissue (Fig.2).

A periodontal probe was used after that to examine the integrity and continuity of the buccal plate of bone. Bovine bone xenograft was then mixed with sterile saline to form a consistent mass and then packed into the extraction socket packed up just up to the alveolar bony margins not extending to the soft tissue margins of the socket. Scrapping was then performed for soft tissue margins to initiate bleeding over the graft particles. In group I, a $980 \mathrm{~nm}$ diode laser (Doctor smile, Italy) was applied in a circular motion to the blood formed at the socket orifice at a power of $1 \mathrm{~W}$ for 1 minute with a continuous wave mode. Application was done without touching the pooling blood and with a nonactivated fiber optic tip. The laser application cycle was repeated 3-5 times to yield a stable fixed blood clot covering the bone graft particles with no oozing blood from its periphery (Fig.3).

In group II, a d-PTFE membrane (Permamem, Botiss biomaterials, Germany) was trimmed to the size of the socket orifice and stabilized a figure of eight suture to the soft tissue margins of the socket with 6-0 vicryl (Unicryl) (Fig.4).

\section{Postoperative instructions}

All patients were instructed to avoid biting and tooth brushing on the surgical site for one week while maintaining a soft diet for the same period. Oral hygiene measures were followed using 0.12 Chlorhexidine gluconate (DG wash. Manufactured by Alesraa for pharmaceuticals and Chemical industries Cairo - A.R.E) twice daily for two weeks. $50 \mathrm{mg}$ of Diclofenac sodium was prescribed 3 times daily for 1 week (Cataflam 50 mg): Manufactured by Novartis (Swiss multinational pharmaceutical company) as an analgesic and antiinflammatory drug. Amoxicillin 875 mg/ clavulanic acid 125 mg (Augmentin1gm: GSK GlaxoSmithKline, England) one tablet every 12 hours for 1 week as a broad-spectrum antibiotic.

\section{Clinical follow-up}

Effect of laser photocoagulation in socket preservation. Patients were recalled after the second, third, and fourth weeks for the examination of the soft tissue healing (Fig.5). For group II patients, the sutures were removed in the first recall visit, 2 weeks postoperatively.

\section{Radiographic follow-up}

After 4 months, a CBCT was made to measure the width of the alveolar ridge at the surgical site using the radiographic stent for the standardization of measurements in the exact cross-section of the preoperative measurements. (Fig. 6)

\section{Statistical analysis}

All quantitative data were presented using mean and standard deviation. Bone width at the cervical, middle, and apical areas were compared using student's t-test. The paired-samples t-test was used to investigate the differences in terms of bone width between the pre- and post-operative procedures. Mann Whitney $U$ test was applied for percent change comparisons. Statistical significant level was set at $\mathrm{p}$-value $\leq 0.05$.

Statistical analysis was performed using the Statistical Package for Social Sciences (SPSS version 25.0, IBM Corp., Armonk, NY, USA).

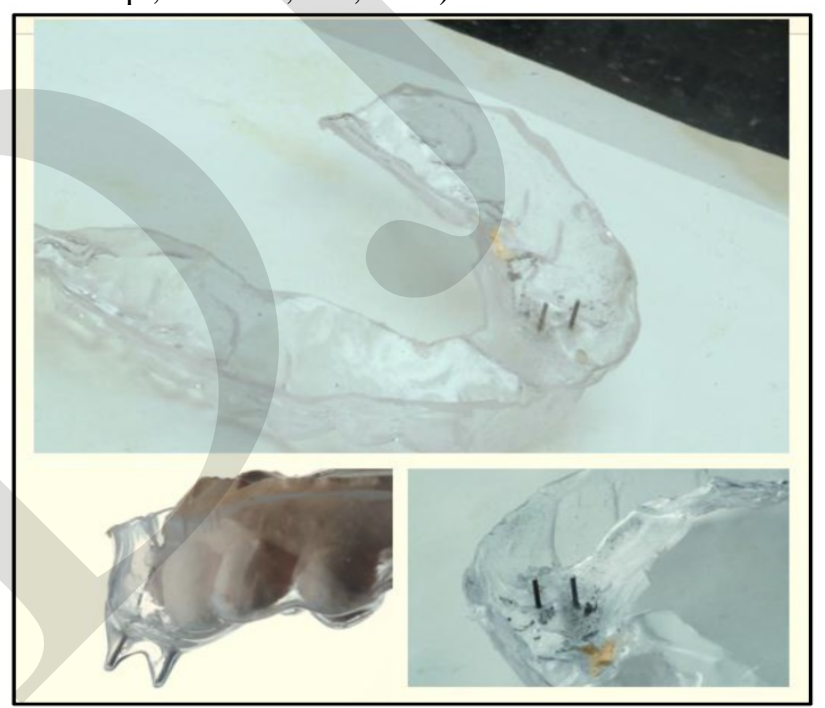

Figure (1): Showing the radiographic stent with the two parallel wires pointing out to the target tooth and trimmed away from the tissues.

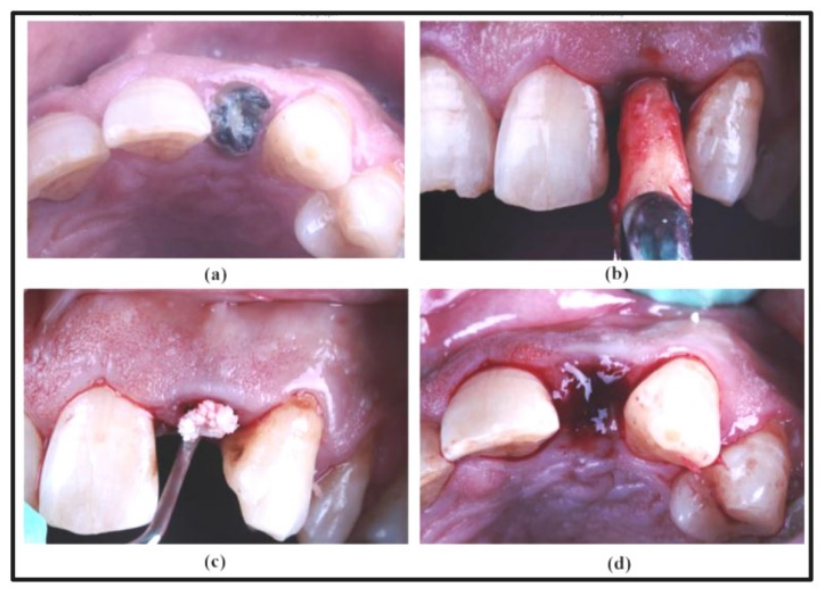




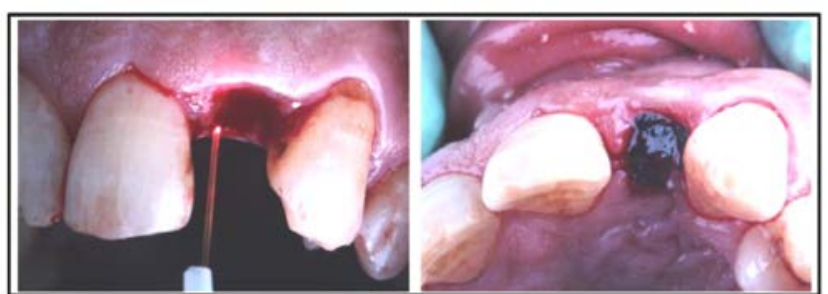

Figure (3): Non-contact laser application with a 320micrometer fiberoptic tip.

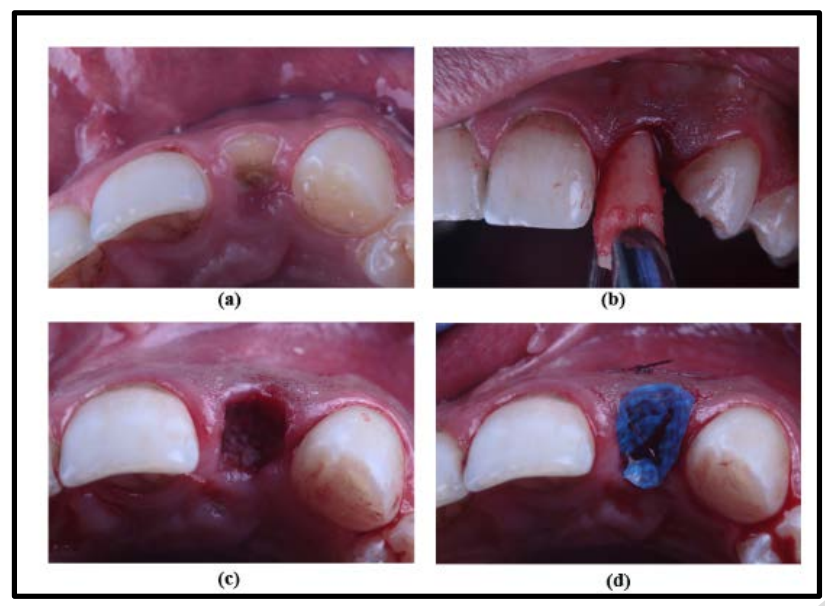

Figure (4): (a) A pre-operative picture of a non-restorable maxillary lateral incisor. (b) Atraumatic extraction using periotomes. (c) Packing the bovine bone xenograft into the socket to the level of the alveolar bone (d) Suturing the membrane to the soft tissue margins of the socket by a figure of eight 6-0 Vicryl suture.

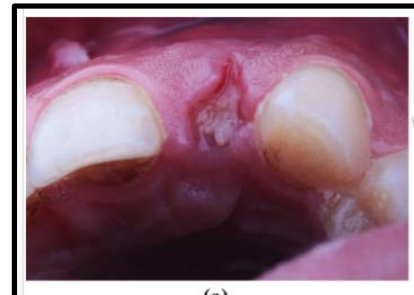

(a)

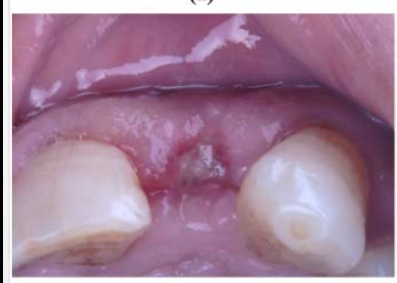

(c)

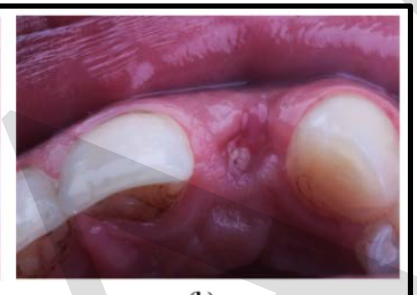

(b)

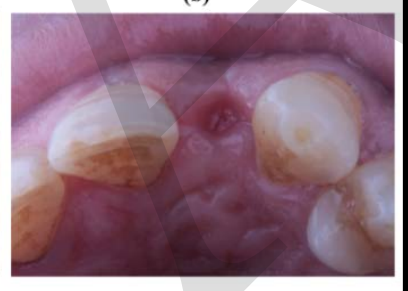

(d)
Figure (5): (a)The healing of the soft tissue after 2 weeks for the membrane group. (b) The healing of the soft tissue after 3 weeks for the membrane group. (c) The healing of the soft tissue after 2 weeks for the laser group. (d) The healing of the soft tissue after 3 weeks for the laser group.
Effect of laser photocoagulation in socket preservation.
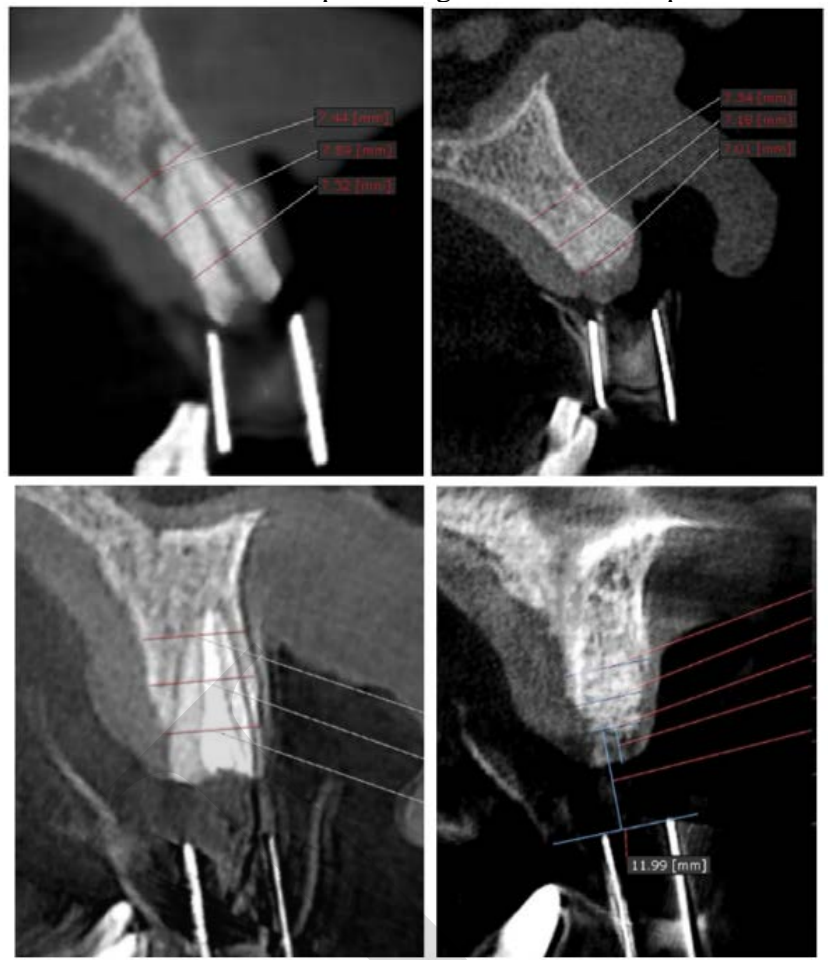

Figure (6): Showing the radiographic picture of the test group (on the left) and the control group (on the right) at baseline and after 4 months. The stent with the parallel wires used to standardize the cross-section on the CBCT.

\section{RESULTS}

This study was performed on thirty-six patients, including fourteen males and twenty-two females, who had hopeless non-restorable maxillary anterior or premolar teeth. The age ranged from 23 to 48 years old with a mean age of 38 years old. The patients were examined clinically after two weeks and radiographically after four months postoperatively.

\section{Clinical follow up}

Concerning the test group, two cases had early exposure of the graft particles in the first week after the surgery. That probably took place due to early clot dislodgment leaving an erythematous area with oozing blood from the socket and bare connective tissue. However, epithelialization took place by the third week with no bleeding and minimal areas of exposed connective tissue. Then complete keratinization of the crestal tissue over the socket took place by the fifth week. Due to the previous complication, the healing time extended to the fifth week whereas the rest of the cases exhibited complete keratinization a week earlier. The rest of the cases went uneventful throughout the healing follow up visits showing a well-organized fibrin clot on the first week. After two weeks, a mature connective tissue plug was present in socket orifice with incomplete keratinization. By the third week, epithelialization from the surrounding tissues started to cover the socket connective tissue plug. After four weeks, complete keratinization of the tissues covering the socket took place. Whereas, for the control group four cases had early membrane loss after the first week among which one case had delayed wound healing exhibiting an erythematous zone of friable granulation tissue with exposed bone graft particles after losing the membrane. By 
Kamal El din et al.

the fourth week, symptoms of erythema and sloughing subsided leaving a uniform socket plug formed of wellorganized tissue with incomplete keratinization. By the sixth week, complete keratinization took place. The rest of the cases went uneventful and showed a mature socket plug after two weeks during the membrane removal with no bleeding or oozing from the socket. Presenting with areas of mature connective tissue with incomplete keratinization in the membrane removal visit. Healing proceeded eventually throughout the third week and complete keratinization of the tissues covering the socket took place after 4 weeks.

\section{Radiographic follow up}

Horizontal ridge dimension was examined at the crest, middle third and apical third on the pre- and post-operative cone-beam computed tomographs to compare the bone dimensional changes between the two study groups

The mean horizontal bone thickness at the alveolar crest in the test group was $6.68(1.36) \mathrm{mm}$ at the baseline and reduced significantly to 5.99 (1.43) mm after 4 months $(\mathrm{P}=<0.0001)$.Similarly, the mean of the control group was $7.37(1.04) \mathrm{mm}$ and reduced to 6.59 (1.00) $\mathrm{mm}$ after 4 months $(\mathrm{P}=<0.0001)$. The mean difference between the 2 groups was $0.69(0.33)$ and $0.78(0.15)$ for the test and control groups, respectively. However, this difference was non-significant $(\mathrm{P}=0.31)$. The percent reduction in horizontal bone thickness at the alveolar crest was 10.76 (5.70) \% for the test group, whereas, it was reduced by 10.66 (5.41) \% in the control group. Yet, no significant difference was found $(\mathrm{P}=0.94)$. Table (1)

The mean horizontal bone thickness of $3 \mathrm{~mm}$ apical to the alveolar crest in the test group was 7.29 (1.41) $\mathrm{mm}$ at the baseline and reduced significantly to 6.73 (1.39) $\mathrm{mm}$ after 4 months $(\mathrm{P}=<0.0001)$.Similarly, the mean of the control group was $7.81(1.49) \mathrm{mm}$ and reduced to 7.23 (1.41) $\mathrm{mm}$ after 4 months $(\mathrm{P}=<0.0001)$. The mean difference between the 2 groups was $0.56(0.36) \mathrm{mm}$ and 0.58 (0.18) $\mathrm{mm}$ for the test and control groups, respectively. However, this difference was non-significant $(\mathrm{P}=0.86)$. The percent reduction in horizontal bone thickness of $3 \mathrm{~mm}$ apical to the alveolar crest was 7.73 (4.34) \% for the test group, whereas, it was reduced by 7.42 (1.83) \% in the control group. Yet, no significant difference was found $(\mathrm{P}=0.77)$. Table (2)

The mean horizontal bone thickness of $6 \mathrm{~mm}$ apical to the alveolar crest in the test group was 7.33 (1.51) $\mathrm{mm}$ at the baseline and reduced significantly to 7.07 (1.50) $\mathrm{mm}$ after 4 months $(\mathrm{P}=0.008)$. Similarly, the mean of the control group was 8.58 (1.83) $\mathrm{mm}$ and reduced to 8.17 (1.73) $\mathrm{mm}$ after 4 months $(\mathrm{P}<0.0001)$. The mean difference between the 2 groups was $0.26(0.36) \mathrm{mm}$ and $0.41(0.17) \mathrm{mm}$ for the test and control groups, respectively. However, this difference was non-significant $(\mathrm{P}=0.12)$. The percent reduction in horizontal bone thickness of $6 \mathrm{~mm}$ apical to the alveolar crest was 3.44 (4.69) \% for the test group, whereas, it was reduced by 4.70 (1.78) \% in the control group. Yet, no significant difference was found $(\mathrm{P}=0.29)$. Table (3)

Table 1: Horizontal bone thickness at the alveolar crest at baseline and 4 months postoperatively.
Effect of laser photocoagulation in socket preservation.

\begin{tabular}{|l|l|l|l|}
\hline & $\begin{array}{l}\text { Bovine bone } \\
\text { xenograft+laser } \\
\text { photocoagulation } \\
(\mathbf{n = 1 8 )}\end{array}$ & $\begin{array}{l}\text { Bovine bone } \\
\text { xenograft+d- } \\
\text { PTFE } \\
\text { membrane } \\
(\mathbf{n = 1 8 )}\end{array}$ & $\begin{array}{l}\text { P } \\
\text { value }\end{array}$ \\
\cline { 2 - 3 } & Mean (SD) & \multicolumn{2}{|c|}{} \\
\hline Baseline & $6.68(1.36)$ & $7.37(1.04)$ & 0.09 \\
\hline $\begin{array}{l}\text { After 4 } \\
\text { months }\end{array}$ & $5.99(1.43)$ & $6.59(1.00)$ & 0.15 \\
\hline $\boldsymbol{P}$ value & $<0.0001^{*}$ & $<0.0001^{*}$ & 0.31 \\
\hline $\begin{array}{l}\text { Mean } \\
\text { difference }\end{array}$ & $0.69(0.33)$ & $0.78(0.15)$ & 0.94 \\
\hline $\begin{array}{l}\text { \% } \\
\text { Reduction }\end{array}$ & $10.76(5.70)$ & $10.66(5.41)$ & \\
\hline
\end{tabular}

*Statistical significance at $\mathrm{p}$ value $\leq 0.05$

Table 2: Horizontal bone thickness $3 \mathrm{~mm}$ apical to the alveolar crest at baseline and 4 months postoperatively.

\begin{tabular}{|c|c|c|c|}
\hline & $\begin{array}{l}\text { Bovine bone } \\
\text { xenograft+laser } \\
\text { photocoagulation } \\
(n=18)\end{array}$ & $\begin{array}{l}\text { Bovine bone } \\
\text { xenograft+d- } \\
\text { PTFE } \\
\text { membrane } \\
(n=18)\end{array}$ & $\begin{array}{l}P \\
\text { val } \\
\text { ue }\end{array}$ \\
\hline & Mean (SD) & & \\
\hline Baseline & $7.29(1.41)$ & 7.81 (1.49) & $\begin{array}{l}0.2 \\
9 \\
\end{array}$ \\
\hline 4 months & 6.73 (1.39) & $7.23(1.41)$ & $\begin{array}{l}0.2 \\
8 \\
\end{array}$ \\
\hline$P$ value & $<0.0001 *$ & $<0.0001^{*}$ & \\
\hline $\begin{array}{l}\text { Mean } \\
\text { difference }\end{array}$ & $0.56(0.36)$ & $0.58(0.18)$ & $\begin{array}{l}0.8 \\
6 \\
\end{array}$ \\
\hline $\begin{array}{l}\% \\
\text { Reduction }\end{array}$ & $7.73(4.34)$ & 7.42 (1.83) & $\begin{array}{l}0.7 \\
7 \\
\end{array}$ \\
\hline
\end{tabular}

*Statistical significance at $\mathrm{p}$ value $\leq 0.05$

Table 3: Horizontal bone thickness $6 \mathrm{~mm}$ apical to the alveolar crest at baseline and 4 months postoperatively.

\begin{tabular}{|c|c|c|c|}
\hline & $\begin{array}{l}\text { Bovine bone } \\
\text { xenograft+laser } \\
\text { photocoagulation } \\
(n=18)\end{array}$ & $\begin{array}{l}\text { Bovine bone } \\
\text { xenograft+d- } \\
\text { PTFE } \\
\text { membrane } \\
(n=18)\end{array}$ & \multirow[t]{2}{*}{$\begin{array}{l}P \\
\text { value }\end{array}$} \\
\hline & \multicolumn{2}{|l|}{ Mean (SD) } & \\
\hline Baseline & $7.33(1.51)$ & $8.58(1.83)$ & $0.03^{*}$ \\
\hline 4 months & $7.07(1.50)$ & $8.17(1.73)$ & $0.04^{*}$ \\
\hline$P$ value & $0.008^{*}$ & $<0.0001^{*}$ & \\
\hline $\begin{array}{l}\text { Mean } \\
\text { difference }\end{array}$ & $0.26(0.36)$ & $0.41(0.17)$ & 0.12 \\
\hline $\begin{array}{l}\text { \% } \\
\text { Reduction }\end{array}$ & 3.44 (4.69) & $4.70(1.78)$ & 0.29 \\
\hline
\end{tabular}

*Statistical significance at $p$ value $\leq 0.05$

\section{DISCUSSION}

This study was conducted on thirty-six patients divided randomly into two study groups, and each group had 18 participants who all continued to the last radiographic follow up with no dropouts. In the laser group, two cases had delayed wound healing after socket preservation in the maxillary premolars. This could be attributed to the large 
Kamal El din et al.

socket orifice or the early dislodgement of the sealing blood clot due to mechanical trauma or lack of compliance to the post-operative instructions and the oral hygiene measures. The complications that occurred were graft particle exposure on the second-week post-surgically and pain in the surgical site that was controlled with simple analgesics. All other cases in the laser group went uneventful showing a plug of well-organized fibrous connective tissue that sealed the orifice of the socket on the second week follow up. Whereas in the d-PTFE membrane group, four cases had an early loss of the membrane in the first week, which could be due to mechanical friction during mastication, yet only one had delayed wound healing up to the sixth week. Another complication that occurred in the membrane group was the rotation of the membrane. When examined after two weeks, two cases had rotated membranes that caused a cleft in the mid buccal soft tissue which remained present after complete soft tissue healing after the fourth week. This could be attributed to the loosening of one of the sutures stabilizing the membrane at its 4 corners. However, no signs of inflammation or delayed healing were sustained beyond the first month.

Bovine bone xenograft was the material of choice in the current study due to its availability, osteoconductive properties, and its space maintenance capacity that holds it superior to autogenous bone graft in minimizing the alveolar bone post-extraction dimensional changes $(15,16)$. The follow-up period for radiographic analysis was determined to be 4 months comparatively with similar socket preservation studies with bovine xenograft to standardize the comparison of the outcomes $(15,29)$.

The choice of the proposed technique for sealing the socket after bone grafting using a 980nm diode laser was based upon its simplicity and availability for a wide range of practitioners. The non-contact laser photocoagulation with a fixed power output is a replicable flapless procedure with less working time and tissue interferences as it comprises no introduction of additional biomaterials than the bone graft requiring less operator training and technique sensitivity. This method was initially tested experimentally by Mirdan et al (26) for its effectiveness of producing a stable blood clot in non-grafted sockets to stimulate bone and soft tissue healing and limit the postoperative complications and was proven to be effective. Yet, no human studies were reported in the literature for similar research to test the efficacy of the $980 \mathrm{~nm}$ diode laser photocoagulation in sealing sockets after socket preservation. The protocol used in the present study for blood coagulation over the graft particles is a modification of the photocoagulation protocol used in human studies for the treatment of vascular lesions that involves the use of 3-watt power output (25). The power used in the proposed method was downgraded to 1 watt to achieve a dual effect of coagulation and biomodulation simultaneously by the effect named as low-level laser therapy (LLLT) to employ its benefits in tissue oxygenation, cellular proliferation and healing (30). There are upper and lower thresholds between which LLLT is effective. The amount of laser energy is either too weak to have any effect outside of these thresholds, or too strong that causes harmful effects to occur that outweigh its benefits (31). The dose of laser irradiation needed to achieve a stable sealing clot varied according to the size of the socket orifice. The watt output was fixed throughout all cases, so
Effect of laser photocoagulation in socket preservation. increasing the irradiation time was the implemented procedure for larger socket orifices. Maxillary lateral incisors needed almost 3 cycles of a 1 minute noncontact 1 -watt continuous wave irradiation while canines and premolars need up to 5 or 6 cycles.

The present study is the first human randomized controlled trial to assess the effect of the non-contact laser photocoagulation as a socket sealing method on the alveolar bone dimensional changes during socket preservation and to compare it to another conventional method. The impact of the $980 \mathrm{~nm}$ diode laser photocoagulation was proven effective in sealing alveolar sockets after socket preservation with bovine bone xenograft regarding the limitation of the underlying bone dimensional changes. However, it requires the availability of the laser device, good patient compliance postsurgically, and a prepared clinical setting for the prevention of laser operational hazards.

For the control group, open healing with the nonresorbable d-PTFE membrane was chosen as a comparable flapless approach due to the small pore size of the membrane and the good tissue compatibility that permit the incomplete wound closure to cover the membrane (21, 22). One important clinical difference in the use of d-PTFE membranes than the expanded PTFE (e-PTFE) is the ease of removal. In the case of the e-PTFE membranes, the pore size permits fiber penetration during healing, which lately requires its dissection from the surrounding tissues during retrieval, whilst d-PTFE membranes do not permit internal tissue integration into the membrane structure (32).

Another important feature of the d-PTFE membranes is their capacity of cell occlusivness, which prevents epithelial and bacterial cells from entering the healing sites which improves bone regeneration in the grafted sockets, and provides better results with respect to socket preservation (33). Therefore, we chose to use dPTFE in the control group of this clinical study. On the other hand, d-PTFE membranes required better operational skill with larger armamentarium than laser photocoagulation for membrane trimming and suturing which demand more operating time as well.

The mean reduction in bone width at the crest after four months was $0.69(0.33) \mathrm{mm}$ and $0.78(0.15) \mathrm{mm}$ for the test and control groups, respectively. However, the difference between the two groups was non-significant $(\mathrm{P}=0.31)$. Similar findings were reported by Cardaropoli et al. in sockets grafted using bovine xenograft and covered with a collagen membrane. A mean horizontal reduction of $0.7 \mathrm{~mm}$ was found in the test group and a $4 \mathrm{~mm}$ reduction in the negative control group undergoing unassisted healing (34). This result is also supported by the earlier and the latest systematic review and meta-analysis by Avila et al. who reported that minimal changes of about 1 mm were detected in the horizontal dimension by different grafting materials as xenogenous and allogenous bone substitutes after socket preservation in type 1 sockets (12, 18).

Previous systematic reviews by Tan et al., (2012) studied dimensional changes in non-grafted sockets and reported a mean reduction of (3.79) $\mathrm{mm}$ in the bone width at the alveolar crest after six months (35), comparable values were reported by Lang et al. and Jambhekar et al. 
Kamal El din et al.

who reported a mean horizontal bone reduction of 2.79 $\mathrm{mm}$ after 3 months of healing (36, 37). The mean horizontal bone reduction in this study was $0.6 \mathrm{~mm}$ and 0.7 $\mathrm{mm}$ for the test and control group, respectively. This signifies the effectiveness of socket preservation with DBBM and denotes the success of the socket sealing methods used in our study. This resulted from the compensation of DBBM to maintain the volumetric stability of the buccal alveolar ridge contour (14). In previous clinical studies, socket preservation using dPTFE membranes demonstrated that the mean horizontal reduction in ridge dimension ranged from -0.3 to -3.8 $\mathrm{mm}(11,14,31,32)$. This diversity, may be attributable to the difference in the surgical techniques, bone graft materials, and the evaluation methodology (38).

Laurito et al., performed a similar technique as the control group in this study using an open healing technique with d-PTFE membranes that were intentionally left exposed and reported a mean horizontal bone reduction of $1.6 \mathrm{~mm}$ (33). These findings resembled greater bone loss compared to our control group which maybe attributed to the inclusion of type II and type III sockets with buccal bone dehiscence, or the inclusion of smokers in the before mentioned studies. Flap elevation also may be considered disadvantageous due to disruption of the periosteal blood supply. Although socket preservation can be successfully performed through a flapless approach in the majority of cases of intact or minimally damaged bony walls (14), Analogous results to our findings were found by lasella et al. and Cardaropoli et al. who reported a mean horizontal reduction of $1 \mathrm{~mm}$ after 4 months (14, 39).

This study had several limitations. Firstly, the selection criteria was only restricted for type I sockets with intact walls which may explain a mean horizontal reduction at the alveolar crest of 0.6 and $0.7 \mathrm{~mm}$ for the test and control groups, respectively. These values are less than those reported by other studies and including sockets with buccal bone deficiency that eventually result in more horizontal bone reduction that intact sockets. Lee et al. included sockets with $50 \%$ or less of buccal bone deficiency and reported a mean horizontal bone reduction of $1.29 \mathrm{~mm}$ and $1.5 \mathrm{~mm}$ at the crest for the test and control groups, respectively. Secondly, selecting only maxillary non-molar teeth for the study and excluding molar teeth. Studies including molar teeth reported higher values of dimensional changes (15). The findings by Sun et al. represented higher values of horizontal bone reduction with a median of $2.3 \mathrm{~mm}$ and $3.9 \mathrm{~mm}$ in the test and control groups, respectively in a sample containing molar and non-molar teeth (38).

Thirdly, smokers were not recruited in this study to minimize the risk of thermal and chemical trauma to the wound and avoid early clot dislodgment in the laser group then the exposure of the underlying particulate graft. From another aspect, studies that included smokers among the sample size reported a higher mean reduction in the ridge width after 4 months (14). The exclusion of teeth with buccal bone deficiency and large molar sockets was to primarily evaluate the new technique of laser photocoagulation in controlled and favorable parameters for socket healing in terms of socket size and integrity of the underlying bony structure. Further studies are needed
Effect of laser photocoagulation in socket preservation. to confirm the efficacy of the technique in various clinical situations. Fourthly, the influence of the buccal bone thickness on the dimensional ridge changes was not recorded in this study. Some studies correlated the increase in the thickness of the buccal plate of bone more than 1 $\mathrm{mm}$ with the smaller amount of dimensional changes (34). While other studies reported no correlations between the initial thickness of the buccal plate and the dimensional changes (14).

This study did not have a negative control, as it is well established in the literature that socket preservation with bovine bone xenograft is significantly effective to limit the post-extraction dimensional changes, and that socket sealing over the graft particles is a mandatory procedure to enhance the soft tissue healing and prevent graft loss (7). Favoring alveolar socket preservation compared to natural healing.

Finally, this study aimed to evaluate the effect of a novel socket sealing technique and compare it to a well established technique in the literature. The novel method was proven effective in achieving an adequate socket seal over the bone graft particles with a comparable amount of dimensional changes.

\section{CONCLUSION}

Inspite of the limitations, the null hypothesis was confirmed by the results of our study. According to our findings, it is concluded that the 980nm diode laser photocoagulation is a safe, predictable, and replicable method of achieving socket sealing over the bone graft particles. Yet, further studies are needed to evaluate the efficacy of the novel laser photocoagulation method in various clinical situations.

\section{CONFLICT OF INTEREST}

The authors declare that they have no conflicts of interest.

\section{REFERENCES}

1. American Academy of Periodontology. Comprehensive periodontal therapy: A statement by the American Academy of Periodontology. J Periodontol. 2011;82:943-9.

2. Chapple IL, Wilson NH. Manifesto for a paradigm shift: periodontal health for a better life. $\mathrm{Br}$ Dent J.. 2014;216:159-62.

3. Barone A, Toti P, Piattelli A, Iezzi G, Derchi G, Covani U. Extraction socket healing in humans after ridge preservation techniques: comparison between flapless and flapped procedures in a randomized clinical trial. J Periodontol. 2014;85:14-23.

4. Araújo MG, Silva CO, Misawa M, Sukekava F. Alveolar socket healing: what can we learn? Periodontol 2000. 2015;68:122-34.

5. Schroeder HE. Development, structure, and function of periodontal tissues. Periodontium: Springer; 1986. p. 23-323.

6. Januário AL, Duarte WR, Barriviera M, Mesti JC, Araújo MG, Lindhe J. Dimension of the facial bone wall in the anterior maxilla: a cone-beam computed tomography study. Clin Oral Implants Res. 2011;22:1168-71. 
Kamal El din et al.

7. Jung RE, Ioannidis A, Hämmerle $\mathrm{CH}$, Thoma DS. Alveolar ridge preservation in the esthetic zone. Periodontol 2000. 2018;77:165-75.

8. Kerr EN, Mealey BL, Noujeim ME, Lasho DJ, Nummikoski PV, Mellonig JT. The effect of ultrasound on bone dimensional changes following extraction: a pilot study. J Periodontol. 2008;79:283-90.

9. Schropp L, Wenzel A, Kostopoulos L, Karring T. Bone healing and soft tissue contour changes following single-tooth extraction: a clinical and radiographic 12month prospective study. Int J Periodontics Restorative Dent. 2003;23:313-23.

10. Araújo MG, Lindhe J. Dimensional ridge alterations following tooth extraction. An experimental study in the dog. J Clin Periodontol. 2005;32:212-8.

11. Kassim B, Ivanovski S, Mattheos N. Current perspectives on the role of ridge (socket) preservation procedures in dental implant treatment in the aesthetic zone. Aust Dent J. 2014;59:48-56.

12. Avila-Ortiz G, Chambrone L, Vignoletti F. Effect of alveolar ridge preservation interventions following tooth extraction: A systematic review and metaanalysis. J Clin Periodontol. 2019;46:195-223.

13. Iocca O, Farcomeni A, Pardiñas Lopez S, Talib HS. Alveolar ridge preservation after tooth extraction: a Bayesian Network meta-analysis of grafting materials efficacy on prevention of bone height and width reduction. J Clin Periodontol. 2017;44:104-14.

14. Cardaropoli D, Roffredo A, Cardaropoli G. Socket preservation using bovine bone mineral and collagen membrane: a randomized controlled clinical trial with histologic analysis. I Int J Periodontics Restorative Dent. 2012;32:421-30.

15. Lee JS, Cha JK, Kim CS. Alveolar ridge regeneration of damaged extraction sockets using deproteinized porcine versus bovine bone minerals: A randomized clinical trial. Clin Implant Dent Relat Res. 2018;20:729-37.

16. Araújo MG, Lindhe J. Socket grafting with the use of autologous bone: an experimental study in the dog. Clin Oral Implants Res. 2011;22:9-13.

17. Horváth A, Mardas N, Mezzomo LA, Needleman IG, Donos N. Alveolar ridge preservation. A systematic review. Clin Oral Investig. 2013;17:341-63.

18. Avila-Ortiz G, Elangovan S, Kramer K, Blanchette D, Dawson D. Effect of alveolar ridge preservation after tooth extraction: a systematic review and metaanalysis. J Dent Res. 2014;93:950-8.

19. Elian N, Cho S, Froum S, Smith RB, Tarnow DP. A simplified socket classification and repair technique. Pract Proced Aesthet Dent. 2007;19:99-104.

20. Landsberg CJ. Implementing socket seal surgery as a socket preservation technique for pontic site development: surgical steps revisited-a report of two cases. J Periodontol. 2008;79:945-54.

21. Barber HD, Lignelli J, Smith BM, Bartee BK. Using a dense PTFE membrane without primary closure to achieve bone and tissue regeneration. J Oral Maxillofac Surg. 2007;65:748-52.

22. Aladmawy MA, Natto ZS, Steffensen B, Levi P, Cheung W, Finkelman $M$, et al. A Comparison between Primary and Secondary Flap Coverage in
Effect of laser photocoagulation in socket preservation. Ridge Preservation Procedures: A Pilot Randomized Controlled Clinical Trial. Biomed Res Int. 2019;2019:7679319.

23. Genovese WJ, dos Santos MT, Faloppa F, de Souza Merli LA. The use of surgical diode laser in oral hemangioma: a case report. Photomed Laser Surg. 2010;28:147-51.

24. Jasper J, Camilotti RS, Pagnoncelli RM, Poli VD, da Silveira Gerzson A, Gavin Zakszeski AM. Treatment of lip hemangioma using forced dehydration with induced photocoagulation via diode laser: report of three cases. Oral Surg Oral Med Oral Pathol Oral Radiol. 2015;119:e89-94.

25. Bacci C, Sacchetto L, Zanette G, Sivolella S. Diode laser to treat small oral vascular malformations: A prospective case series study. Lasers Surg Med. 2018;50:111-6.

26. Mirdan BM. A 980nm Diode Laser Clot Formation of the Rabbit's Dental Sockets after Teeth Extraction. Iraqi J Laser. 2012;11:37-42.

27. O'Leary TJ, Drake RB, Naylor JE. The plaque control record. J Periodontol. 1972;43:38.

28. Saghaei M. Random allocation software for parallel group randomized trials. BMC Med Res Methodol. 2004;4:26.

29. Koo TH, Song YW, Cha JK, Jung UW, Kim CS, Lee JS. Histologic analysis following grafting of damaged extraction sockets using deproteinized bovine or porcine bone mineral: A randomized clinical trial. Clin Oral Implants Res. 2020;31:93-102.

30. Chen AC, Arany PR, Huang YY, Tomkinson EM, Sharma SK, Kharkwal GB, et al. Low-level laser therapy activates NF-kB via generation of reactive oxygen species in mouse embryonic fibroblasts. PLoS One. 2011;6:e22453.

31. Chung H, Dai T, Sharma SK, Huang YY, Carroll JD, Hamblin MR. The nuts and bolts of low-level laser (light) therapy. Ann Biomed Eng. 2012;40:516-33.

32. Ronda M, Rebaudi A, Torelli L, Stacchi C. Expanded vs. dense polytetrafluoroethylene membranes in vertical ridge augmentation around dental implants: a prospective randomized controlled clinical trial. Clin Oral Implants Res. 2014;25:859-66.

33. Laurito D, Lollobrigida M, Gianno F, Bosco S, Lamazza L, De Biase A. Alveolar ridge preservation with nc-HA and d-PTFE membrane: a clinical, histologic, and Histomorphometric study. Int J Periodontics Restorative Dent. 2017;37:283-90.

34. Cardaropoli D, Tamagnone L, Roffredo S, Gaveglio L. Relationship between the buccal bone plate thickness and the healing of postextraction sockets with/without ridge preservation. Int J Periodontics Restorative Dent. 2014;34:211-7.

35. Tan WL, Wong TLT, Wong MCM, Lang NP. A systematic review of post-extractional alveolar hard and soft tissue dimensional changes in humans. Clin Oral Implants Res. 2012;23:1-21.

36. Lang NP, Pun L, Lau KY, Li KY, Wong MC. A systematic review on survival and success rates of implants placed immediately into fresh extraction sockets after at least 1 year. Clin Oral Implants Res. 2012;23:39-66. 
Kamal El din et al.

37. Jambhekar S, Kernen F, Bidra AS. Clinical and histologic outcomes of socket grafting after flapless tooth extraction: a systematic review of randomized controlled clinical trials. J Prosthet Dent. 2015;113:371-82.

38. Sun DJ, Lim HC, Lee DW. Alveolar ridge preservation using an open membrane approach for sockets with bone deficiency: A randomized controlled clinical trial. Clin Implant Dent Relat Res. 2019;21:175-82.

39. Iasella JM, Greenwell H, Miller RL, Hill M, Drisko C, Bohra AA, et al. Ridge Preservation With Freeze-Dried Bone Allograft and a Collagen Membrane Compared to Extraction Alone for Implant Site Development: A Clinical and Histologic Study in Humans. J Periodontol. 2003;74:990-9. 